\title{
Geotechnical characterization and modelling of the "Fallen Lands" phenomenon in the amazon environment
}

\author{
Elias Santos Souza 1, Nilton de Souza Campelo ${ }^{1,}{ }^{*}$, Raimundo Humberto Cavalcante Lima ${ }^{2}$ and René Levy \\ Aguiar 3 \\ ${ }^{1}$ Civil Engineering Department, Federal University of Amazonas (UFAM), Civil Engineer MSc., Brazil. \\ ${ }^{2}$ Geoscience Department, Federal University of Amazonas (UFAM), Associate Professor D.Sc., Brazil. \\ ${ }^{3}$ Civil Engineering Department, Amazonas State University (UEA), Full Professor D.Sc., Brazil.
}

Global Journal of Engineering and Technology Advances, 2021, 09(03), 122-132

Publication history: Received on 15 November 2021; revised on 18 December 2021; accepted on 20 December 2021

Article DOI: https://doi.org/10.30574/gjeta.2021.9.3.0168

\begin{abstract}
In many rivers of the Amazon, mainly along the Amazon River, the phenomenon of "fallen land" occurs at the time of the rivers' ebb, causing the erosion of river banks, resulting in major social and economic problems. The influence of saturation/percolation of soil layers on the shear resistance of the affected massifs is unknown. Thus, the main objective of the characterization and geotechnical modelling of these slopes is to determine the shear strength of the affected massifs. For this purpose, deformed and undeformed samples were collected from the various layers of the soil massif in a location where the phenomenon was under development. These samples were characterized physically, chemically, and mechanically. Subsequently, the massifs were recreated in reduced scale models, observing the critical conditions in which the disaster occurred, and qualitatively comparing them with slope stability computational models. The results showed that the layers are classified as silty and sandy soils, with a small fraction of clay, and that there are three types of movements associated with the fallen soils: the fall, overturning, and rotational landslide, all actively influenced by the effects of the river's ebb, saturation/percolation, and texture.
\end{abstract}

Keywords: Fallen Lands; Slope Stability; Percolation; Riverbank Erosion; Geotechnical Modelling

\section{Introduction}

The "Fallen Lands" in the words of the researchers [1] are attributed to the process of undermining the banks of large rivers, which in the post-phase of occurrence causes changes in the morphology of the drainage patterns of the channels. Undermine is understood as the rupture of bank river slopes by erosion and water action.

[2] makes an interesting pondering of what the phenomenon is in the view of those living on the banks directly affected:

Fallen lands is a regional Amazonian terminology used mainly to designate the entire process of lateral river erosion as landslide, collapse, landslip, and sinking.

[3] recognized the following factors that cause the occurrence of Fallen Lands: climate, river erosion, water infiltration in the soil, and anthropic action (on a smaller scale). This definition should be further clarified, especially regarding climate, which [1] teach that this erosive modality is triggered by a combination of factors, where it stands out in a degree of importance, the climatic, given the high rainfall levels of this region, estimated at around 2,600 mm/year.

\footnotetext{
${ }^{*}$ Corresponding author: Nilton de Souza Campelo

Civil Engineering Department, Federal University of Amazonas (UFAM), Full Professor D.Sc, Brazil.

Copyright (C) 2021 Author(s) retain the copyright of this article. This article is published under the terms of the Creative Commons Attribution Liscense 4.0.
} 
By consulting the unique bibliographies of Soil Mechanics such as $[4,5,6,7,8,9]$, and so forth, specifically on mass movement and pore-pressure in the soil, it is observed that this study is indispensable to the subject brought up, since the percolation study lends itself to a large number of practical problems, such as stability because the effective stress (which commands the resistance of the soil) depends on pore-pressure, which in turn depends on the stresses caused by water percolation.

As can be observed regarding the fallen lands, there is a favorable environment for the salutary development of research, because the examined texts present complementing views to cover the range of engineering knowledge; however, the views are not replaceable e.g., Geology, by definition, studies the matters that form the globe and mechanism of its formation, whereas physical geography focuses on the analysis of the natural elements of the Earth's space addressing the characteristics of the Earth, its dynamics and natural elements such as climate, relief, geology, topography, vegetation, hydrography, among others. In the consultations made, only their visions were given space.

[10] and [11] conclude in their recent works that better examination of data related to the strength of materials and rupture surfaces is required to study this differentiated phenomenon (suis generis of the Amazon), because data on the properties of materials from riverbanks are insufficient from the geotechnical perspective.

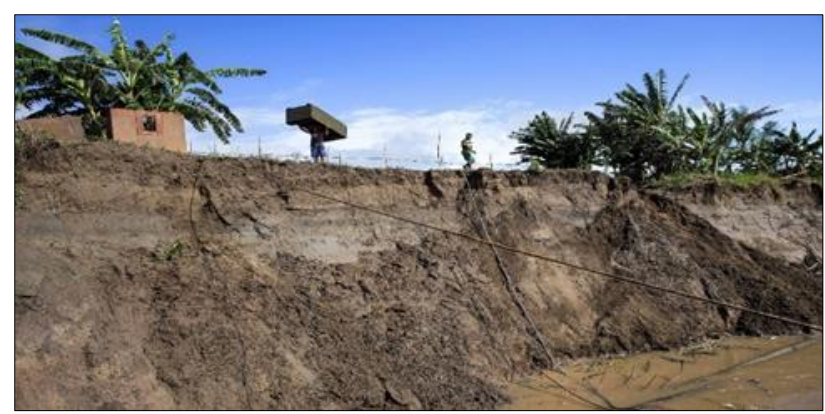

Figure 1 Residents leave their homes as the fallen land approaches. Source: Estarque (2008)

This physical problem was treated with rigorous scientific principles doing an exemplary job by focusing on the examination, characterization of variables, and description. However, it did not solve this dangerous issue completely. This has been reiterated in the criticism of [2] and has been reinforced by [12] and [1] as follows: the insignificant amount of research on this topic and the superficiality of the available research has treated the phenomenon of fallen land only as a minor figment in the piece of Amazonian nature. This paper humbly intends to fill this scientific gap, and attempts to understand this issue further along with other available data.

In summary, we have the ideal starting point for the investigations commonly found in Geotechnical Engineering, because the phenomena of fallen land occurring in the soil must be categorically examined, classified, and tested as per prelects of the soil mechanics in force. In addition, any other constitution of the massif which is part of other types of soils (that have also gone through the same checks), must be thoroughly examined and assembled proportionally (in scale) in a laboratory such that the phenomenon can be artificially recreated (simulated), observed and equated, bringing the physical-mathematical proof of the mechanism of occurrence of the phenomenon in the natural environment and behavior of the possible solutions when the similar conditions of nature are imposed proportionally.

\section{Background}

\subsection{Land Falling in broad and stricto sensu}

Fallen land is a typical Amazonian erosive phenomenon. Owing to its typical nature, it is understood that it occurs annually immediately after the ebb. Moreover, its place of occurrence is typical because it always occurs on the banks of muddy rivers.

The concept of the fallen land is already well explained as erosion in relatively new rivers. This no longer represents in our research the fallen lands in stricto sensu, a phenomenon that pervades geography, geology, and geotechnics (a branch of civil engineering concerned with the resolution of issues involving soils, rocks, and their interactions with structures). This research, in a stricter sense, essentially focuses on the concept to fragment the issue, understand each of its parts, and then recreate it on a smaller scale for one to understand and describe its nature with engineering tools 
and languages. Throughout the revisions and steps followed in this study, the engineering tools and language will be exposed to find the solution or at least to exercise some control over the problem.

However, we must explore the concept of fallen lands to a greater extent, to allow the technician and ordinary people, who are most affected as per our perspective. Therefore, we have described the phenomenon in lato sensu.

This broad description of the phenomenon seeks to present the human, economic and social factors of this natural event. Although this research has a minor role (or influence), it does not mean that people, their movable and immovable assets will not be affected. Quite the contrary. This research and all efforts are directed at them.

The fallen lands are far beyond the occurrence of landslides. It is a process that involves many elements, people, and government agencies because of rehabilitation of affected people, which changes the status of affected people most of the times e.g., leaving the countryside to settle in urban areas, loss of their local identity and assets. The phenomenon of fallen land is changing owing to global climatic events, and silting up of rivers, among others, as in Figure 1.

\subsection{The geotechnical/geological process (the phases) of the Fallen Lands}

The fallen land described in the meticulous evaluation of [2] is in the Amazon River, resulting from the lateral erosion involving a complex process of simultaneous landslip (a), collapse (b), and landslide (c). The mechanism of these processes is explained in detail in the following paragraphs.

\subsubsection{Landslip}

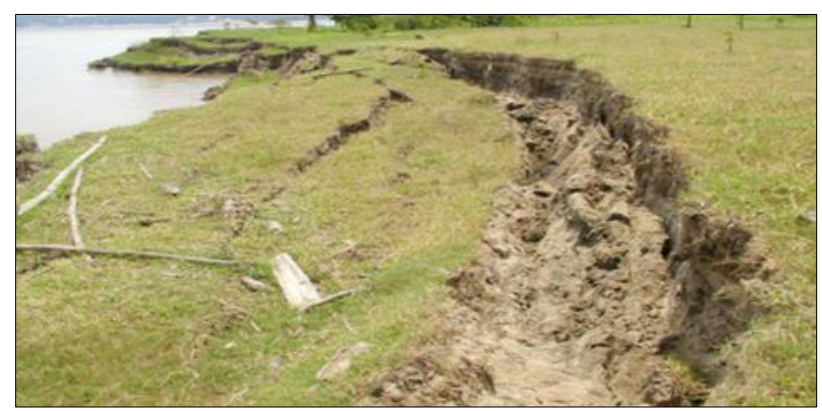

Figure 2 Example of landslip, in Careiro/AM. Source: Nunes (2004) apud Carvalho (2006)

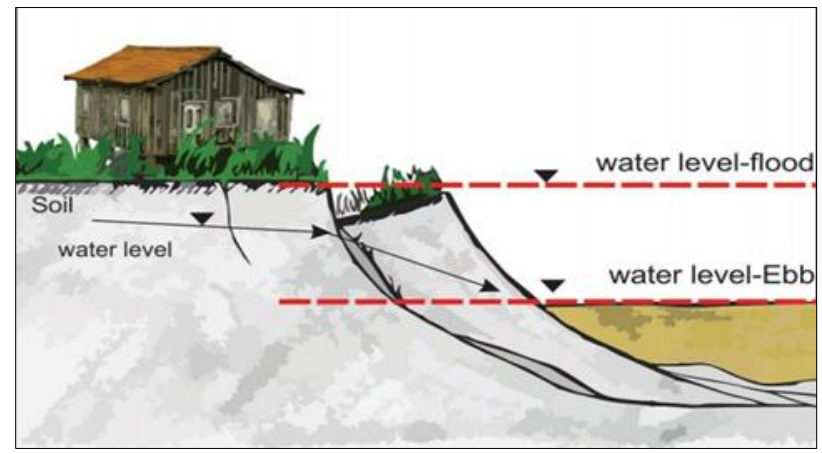

Figure 3 Illustrative profile of the landslip on the ebb. Source: Bandeira et al. (2018), p. 7.

The eminent geologist [13] described this phenomenon as the one characterized by the rapid sliding of a relatively less coherent body of rock or regolith along the curved rupture surfaces. According to [4] and Carvalho [2], it is a rapid displacement of a rocky mass, residual soil, or adjacent sediments from a slope in which the center of gravity of the moving mass advances in an outward-oriented direction (see Figure 2 below). In the Miracauera/AM research conducted by [2], the landslip is considered as a much slower mass movement of perceptible observation. such as to consequently alert the occupants of the region of occurrence. In addition, its occurrence was strongly attached to the period of river ebb, as shown in Figure 2 and its respective behavioral scheme is shown in Figure 3. 


\subsubsection{Collapse}

It is associated with the rapid descent of material along with the formation of irregular-looking hills at the bottom of the slope (foot). Christofoletti along with [14] describes this phenomenon as the one commonly occurring on the river banks owing to the rapid movement of a block of soil or rock, when the undermining creates a void in the lower part of the slope. In [2], this process is explained as the rapid movement of the material with a rupture plane very close to $90^{\circ}$. This may be attributed to the saturation of the soil in the periods of flood and it remains saturated because of the ebb and breaks on account of the increased stress owing to greater specific weight. Figure 4 and Figure 5 illustrate all the dimensions of the phenomenon.

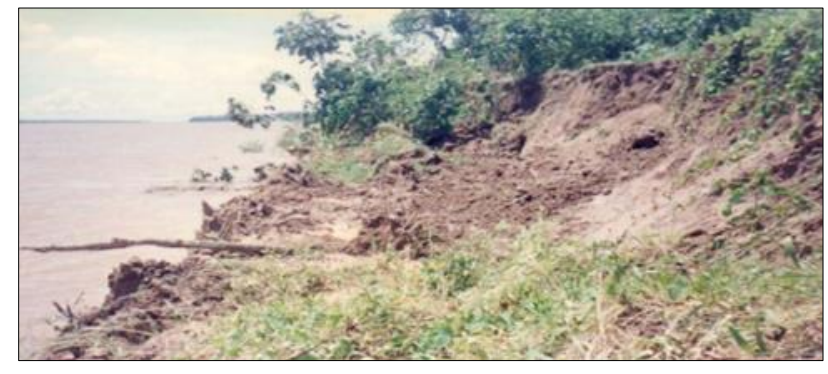

Figure 4 Example of collapsing. Source: Carvalho (2006)

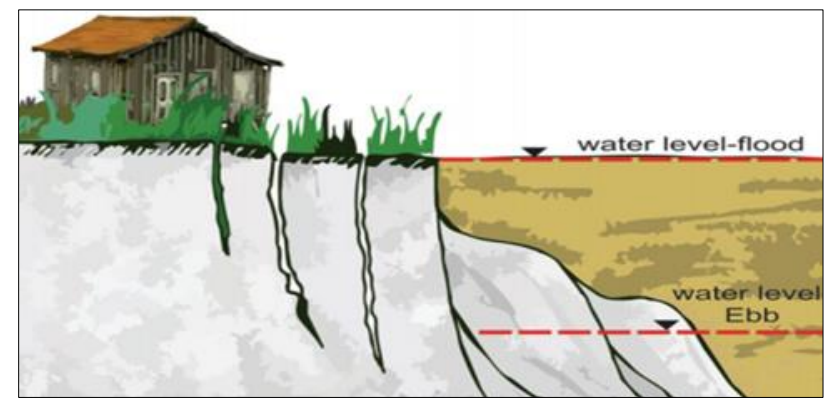

Figure 5 Schematic of collapse during flooding. Source: Bandeira et al. (2018), p. 7

\subsection{Landslide}

It is also an abrupt form of mass sliding; however, this occurs randomly without a well- defined sliding surface. and the shape of the released mass. As per [15], if there is a sliding surface, it occurs by gravity. The following are the characterizations of the phenomenon subtype as illustrated in Figure 6 and Figure 7.

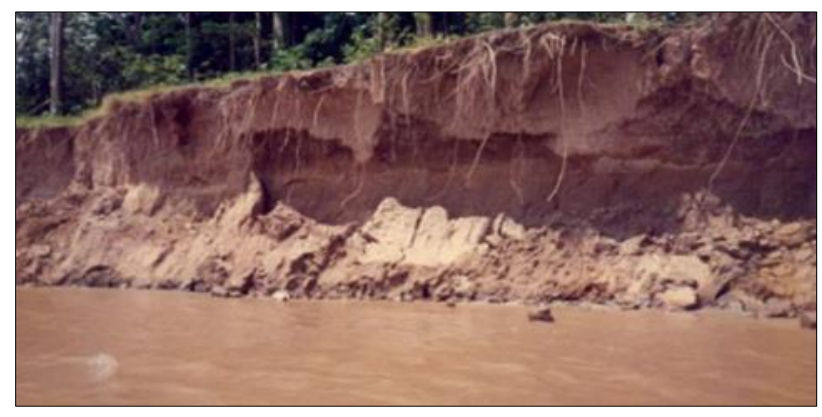

Figure 6 Example of the abrupt and random movement of the landslide. Source: Carvalho (2006)

[2] makes another contribution to this study, mentioning that these three processes come, mainly, from the action of the "banzeiros" meaning waves like sea waves, the wind and even the boats that move the water, forming waves that dissipate on the banks of the bodies of water. It can be observed that this area of research has a lot of scope for investigation, although only a few concepts are already developed and consolidated for improvement or comparison. 
Finally, we must consider the findings of the study conducted by [11]. It was inferred from this study that the involved processes (of fallen lands) are intrinsically associated with the effects caused by the infiltration of rainwater and demands imposed by river dynamics such as erosion and level oscillation.

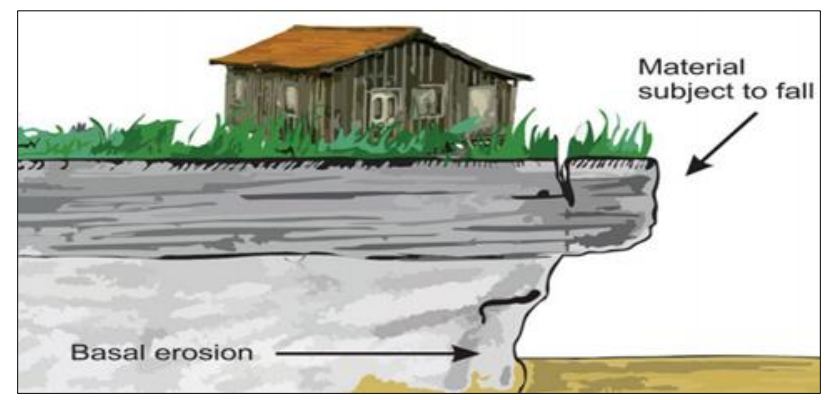

Figure 7 Landslide scheme. Source: Bandeira et al. (2018), p. 7

Once this stage of verification of phenomenon development is complete in a pure (and globally) geological perspective, the question arises as to, how the fallen land occurs mathematically and physically, in the purview of civil engineering (a subarea of geotechnics).

\section{Methodology}

\subsection{On-site investigations}

The chosen study region is located in the municipality of Careiro da Várzea/AM (with geographical coordinates are $3^{\circ} 11^{\prime} 51^{\prime \prime} \mathrm{S}$ and $59^{\circ} 49^{\prime} 32^{\prime \prime} \mathrm{W}$ ), whose headquarters is approximately $17 \mathrm{~km}$ from the capital Manaus in the state of Amazonas. Although the study area is in the above municipality, the designated place is closer to the capital Porto da Ceasa, approximately $7 \mathrm{~km}$ away from the eastern zone of the capital, situated on the right side of the banks of the Amazon River, as shown in the figure below:

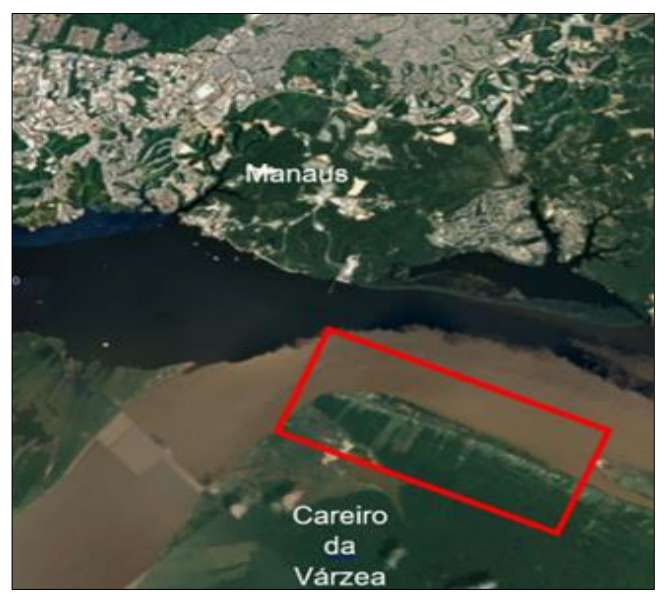

Figure 8 Study Area

In this region, several occurrences of the previously described subtypes of the phenomenon are observed, which allows further qualitative modelling of the phenomenon. 


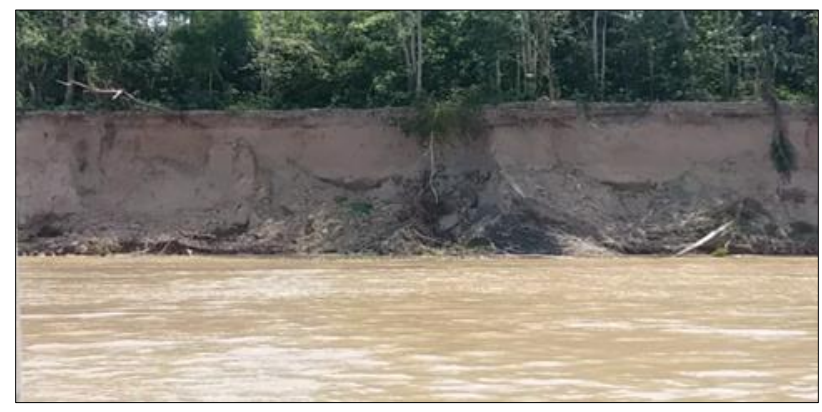

Figure 9 Bank affected by the phenomenon. According to news, it collapsed the night before our visit

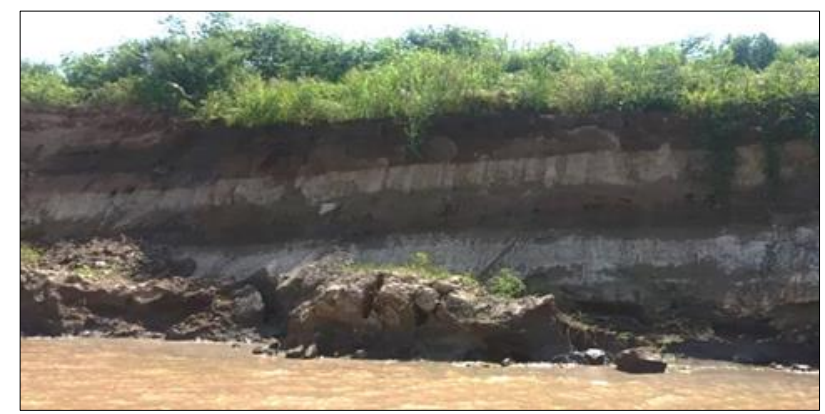

Figure 10 Clearly distributed stratification. It is observed that the layers have different types of moisture. The detachment of the soil takes place in this place in large blocks

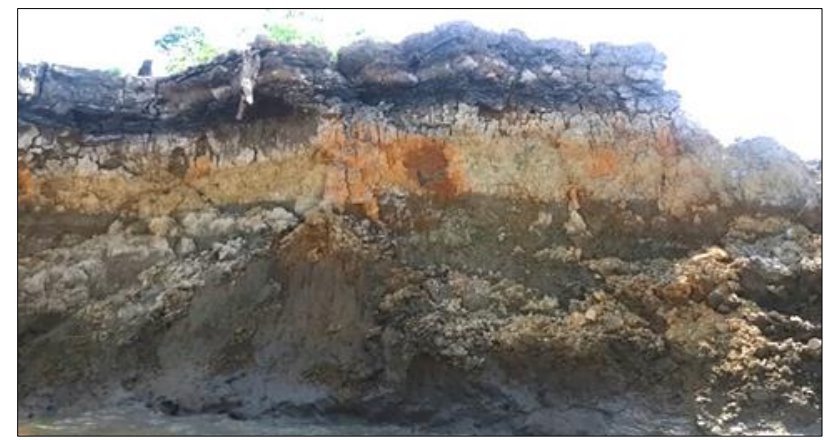

Figure 11 Image of the layers that will be modeled in the reconstruction of the phenomenon in the laboratory. Once again, mottled clay and noticeable variations in moisture are highlighted

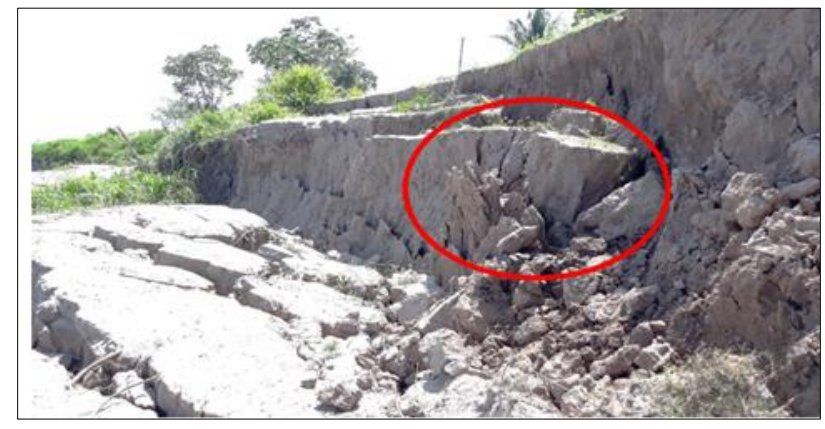

Figure 12 View of the collapsed block from the inside. There is a marked presence of the soil known as "Mottled" (slightly reddish) with sandy pockets 


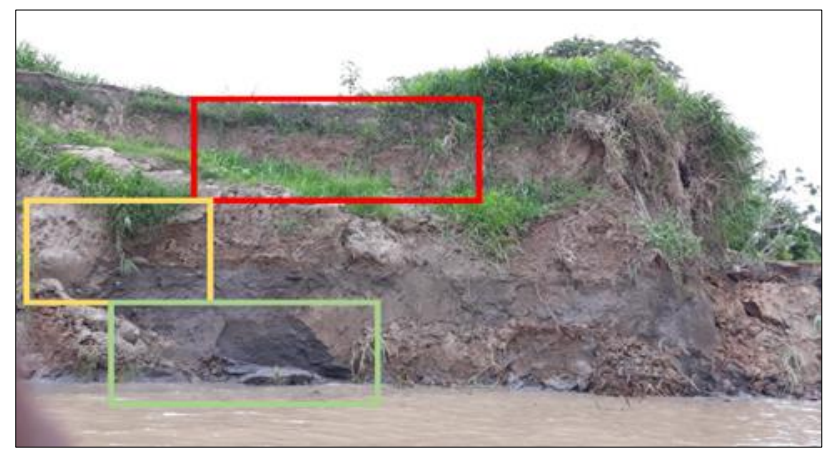

Figure 13 Observation of the representative massif. In this, there is the presence of the three layers that this study proposes to characterize, being red for Mottled soil, yellow for White soil and green for Gray soil

\subsection{Materials and testing}

According to Brazilian technical standards, the important tests such as specific weight, Attenberg limits, classification, compaction, direct Shear, simple compression strength, and hydraulic conductivity were followed for characterization of the soil of the formed structures.

\subsection{Physical and computational modelling}

In order to develop a physical model, the field observations and laboratory results of materials present in the areas of occurrence were used to recreate a qualitative model on a reduced scale to help understand the phenomenon. A bench of adapted hydraulic conductivity was used for this study such that it supported the types of soils in proportional layers, in conditions of disposition and compaction similar to the natural conditions. Moreover, the conditions were such that it saturated the sample and then gradually emptied, as in an ordinary cycle of floods and droughts occurring in the region, to simulate subtypes of fallen lands.

In the computational modelling stage, the well-known GE05@ software and the Slope/Seep-Geostudio@ coupling were applied, with the generation of slope balance and slope hydraulic conductivity scenarios based on the tests (classification, specific weights, cohesion, angle of friction and hydraulic conductivity) of the obtained materials, and the characteristics of the site (layout and thickness of layers via exploratory drilling and observation of slope faces).

\section{Results and discussion}

\subsection{About materials}

Considering the evaluation of the materials collected in the field, the individual material study has greatly contributed to the understanding of the phenomenon. Based on the granulometry, high percentages of sandy and silty soils, especially "white" and "grey" soils, were observed. This observation was supported by results obtained from the shear resistance test. Moreover, these soils tend to have less or no cohesion in the unconfined state, as observed in a simple compression test.

The high level of saturation and high percentage of voids also prove to have a major influence on the rupture system of natural massifs, because the reduction of contact between the grains impacts the resistance of soil (Table 1).

A significant amount of water is naturally present in the soil. Therefore, the hydraulic conductivity of soil is a key element to understand changes in the stress of a given portion of soil (Table 2). The layers in the center (pockets of the soil "white") and base ("grey") are much more permeable than the upper layer ("mottled"), making the geostatic stresses of these layers always higher than the descent of the river level. Therefore, these less resistant layers result in breaking up with large amounts of internal water.

The shear strength (Table 3), which is a fundamental study for the development of computational models for hydraulic conductivity and rupture of the massifs, was performed solely by the conditions of the equipment, the rupture without submergence of the samples, in their natural condition (undeformed). The results were very interesting for the visualization of the forms of mass movements that can occur in fallen lands, mainly by the soil that composes the base and center of the massifs, which has low or almost zero cohesion resulting in abrupt rupture, leaving in some cases the cohesive soil layer ("mottled") behind as in landslip or rupturing it together as in landslide, depending on the time. A 
special addendum is made on the "grey" soil which, as already mentioned, remains in the lower layers, and basically passes the entire cycle of flood/leakage submerged and thus presents very low resistance to cutting, as observed in the relevant part. This shows a formidable natural condition for certain types of rupture.

Based on the granulometry analysis, consistency limits, and soil classification, it is reported that the soils analyzed in this research stand out for their expressive sandy and silty partitions, because the "white" soil is naturally fine sand of good graduation, while the "grey" soil is silty sand with plastic behavior (even if low concerning PI), and the "mottled" soil is the most differentiated of the three, for being sandy silt in nature with fully active clay partition $(\mathrm{AI}=7.18)$, that makes the soil behave like clay. The classification of all soils was made according to both the SUCS and AASHO systems through which it would be possible to obtain previous behavioral information partly without adding significant value to the study.

In the verification of mineralogical and chemical composition of the soils, the high portions of quartz stand out mainly owing to the presence of sand in all soils. For soils with a certain cohesion, either provided by the silt or by the clay, a varied range of aluminosilicates, sodium, potassium, and calcium silicates was observed.

Table 1 Physical properties of undeformed soil samples

\begin{tabular}{|l|l|c|c|c|c|c|c|}
\hline \multirow{2}{*}{ Soil } & \multicolumn{1}{c|}{$\boldsymbol{\gamma}_{\mathbf{n a t}}$} & $\mathbf{w n a t}$ & $\boldsymbol{\gamma}_{\mathbf{d}}$ & $\boldsymbol{\gamma}_{\mathbf{g}}$ & $\mathbf{e}$ & $\mathbf{n}$ & $\mathbf{S}$ \\
\cline { 2 - 8 } & $\mathbf{k N} / \mathbf{m}^{\mathbf{3}}$ & $\mathbf{\%}$ & $\mathbf{k N} / \mathbf{m}^{\mathbf{3}}$ & $\mathbf{k N} / \mathbf{m}^{\mathbf{3}}$ & & $\mathbf{\%}$ & $\mathbf{\%}$ \\
\hline Mottled & 16 & $28,72 \%$ & 12,43 & 26,26 & 1,11262 & $52,67 \%$ & $67,78 \%$ \\
\hline White & 15 & $16,88 \%$ & 12,83 & 26,14 & 1,03683 & $50,90 \%$ & $42,56 \%$ \\
\hline Grey & 16,5 & $38,13 \%$ & 11,95 & 26,24 & 1,19669 & $54,48 \%$ & $83,61 \%$ \\
\hline
\end{tabular}

Table 2 Hydraulic Conductivity of the samples

\begin{tabular}{|c|c|c|c|c|}
\hline Soil & $\mathbf{k}$ - Coef. of Hyd. Cond. (m/s) & $\mathbf{A ~ ( \mathbf { m } ^ { 2 } )}$ & $\mathbf{i}(\mathbf{h} / \mathbf{L})$ & $\mathbf{Q}(\mathbf{l} / \mathbf{d a y})$ \\
\hline White & $2,50411 \mathrm{E}-04$ & 1 & 1 & $21.635,54399$ \\
\hline Grey & $6,04664 \mathrm{E}-08$ & 1 & 1 & 5,224295318 \\
\hline Mottled & $5,20071 \mathrm{E}-09$ & 1 & 1 & 0,449341402 \\
\hline
\end{tabular}

Table 3 Direct shear tests of the samples

\begin{tabular}{|c|c|c|c|}
\hline Soil & Sample & Cohesion (kPa) & phi ( ${ }^{\circ}$ ) \\
\hline White & AR.CS-1 & 14,234 & 29,52 \\
\hline White & AR.CS-1 & 11,563 & 29,98 \\
\hline Mottled & MOS.CS-1 & 40,723 & 24,47 \\
\hline Mottled & MOS.CS-2 & 54,800 & 22,1 \\
\hline Grey & CZ.CS-1 & 4,3309 & 30,82 \\
\hline Grey & CZ.CS-2 & 1,9608 & 31,22 \\
\hline
\end{tabular}

\subsection{On physical and computational modelling}

The models in a reduced scale constituted better visualization of the fallen lands. They were developed mainly for qualitative and parametric analyses because over a series of boundary conditions of Ceteris paribus was applied. With the other conditions not applied, it was sought to see how the massifs went through the process of rupture. With this set of tests, we saw the three types of movements associated with the fallen earth, the most emblematic cases being the 
collapsing movement, which is preceded by dismantling of the most granular layers simply leaving behind the clay layer maintained by the cohesion of the particles. The collapsing movement occurs for a similar reason, except for the swing part, because in this case, the massif breaks up into blocks and the slipping movement (wedge descent of the entire massif), which has a greater occurrence (as well as the collapsing) in the descent of the river level (in this case in the drainage of the fluid used).

Based on computational modelling, there were relevant differences in the breaking mechanisms between the used systems. A significant part of the difference lies in the degree of sophistication (limits) in each of them. GE05(C) disregarding a series of variables presented simpler results. We noticed a direct correlation between the reduction of the safety factor and the adopted water level, and the rupture of the massif in sandy layers when the water level reached them. Such issues are observed in the field.

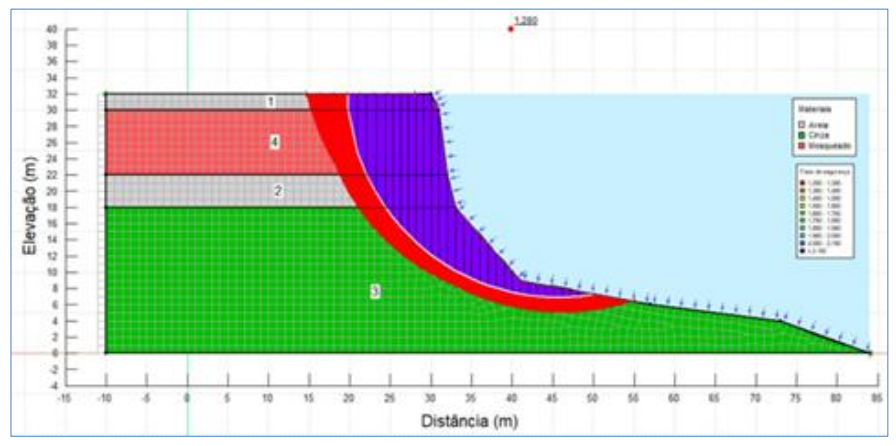

Figure 14 Standardized model in Geostudio (C) for analysis of breaking wedges, safety factors and percolation paths

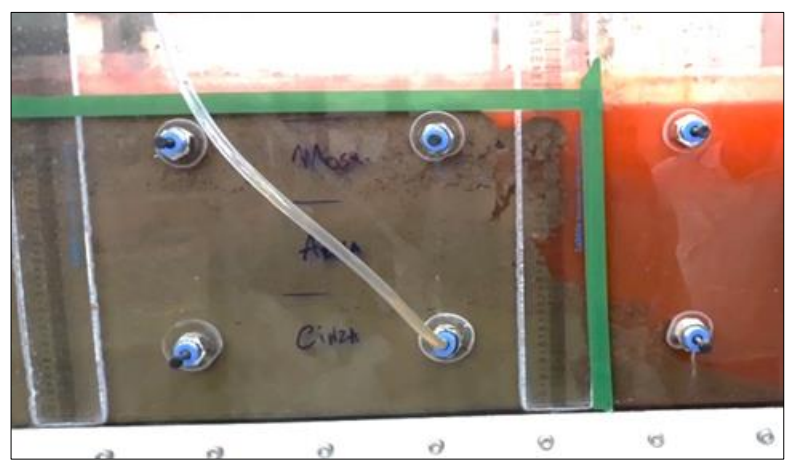

Figure 15 Pre-test model, with green adhesive tapes to delimit the shape before removing the permeable plate

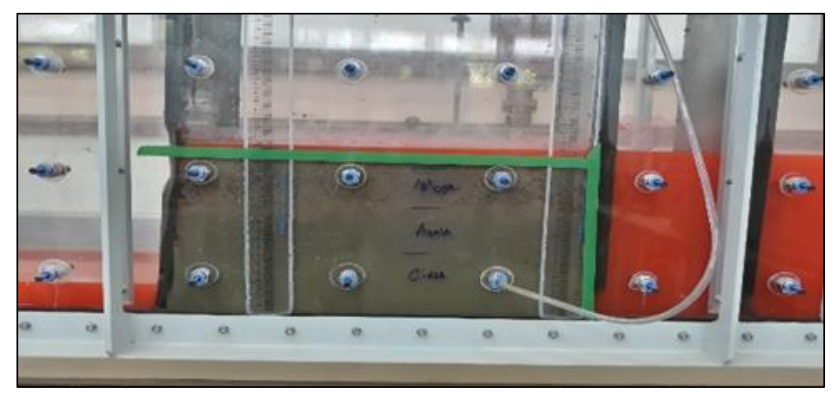

Figure 16 Increased erosion of the sandy layer, leaving the soil layer mottled in balance 


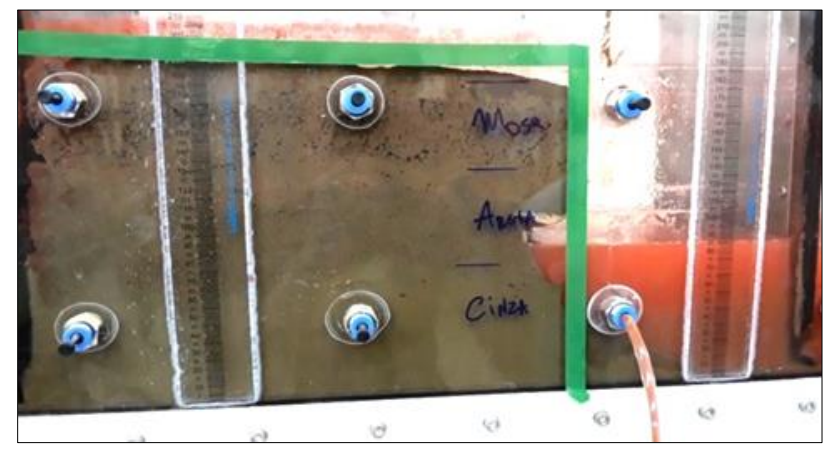

Figure 17 Collapse of part of the edge of the massif. The landslide is cited as the movement that occurred, as the water level was static

The use of Geostudio (C managed to overcome the capacities of the previous system, mainly by modelling $n$-scenarios and by allocating more variables (hydraulic conductivity, river regime, among others). All these issues provided a more integral view of the fallen lands by the slope stability bias. The main conclusions emphasize the importance of the water level on stabilization of the massif, the unstable balance that the river banks are constantly facing according to the theory (and norm) of slope stability, and the ways natural disposition of the layers may or may not generate greater security.

The computational modelling and reduced scale simulations mostly show a parametric character or in a more appropriate way, a qualitative evaluation of the phenomenon that makes use of numerical tools to describe approximately the probability of occurrence of the fallen lands.

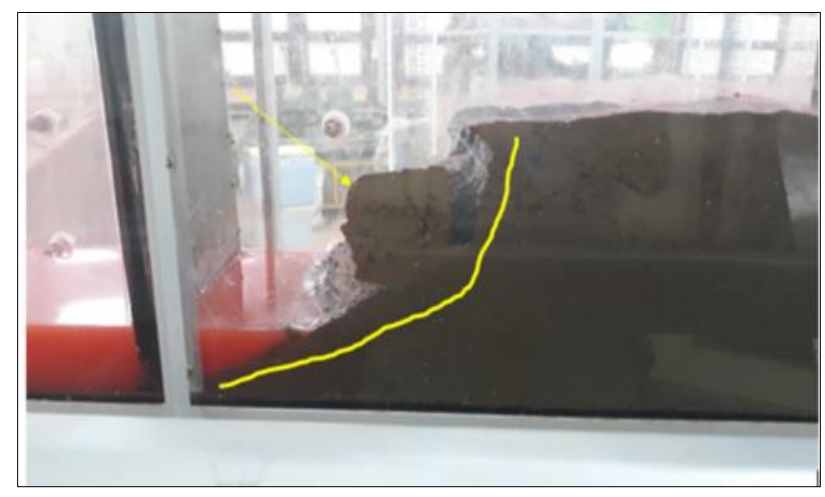

Figure 18 Sliding movement. It is observed that the movement actually formed a wedge (highlighted) on the remaining margin and preserved a part of the massif, after the waters descend, as in Figure 5, on the slip that occurs in the ebb of the river (schematic profile)

\section{Conclusion}

As noted, the initially defined landslide failure models were positively proven through physical, chemical and mechanical characterization tests of the collected soils, small-scale and computational models, as well as the determining reasons for their occurrence, such as the natural disposition of the layers, granulometric composition, the variation of river levels, hydraulic conductivity and shear strength, which alters the balance of the river banks at each annual cycle of flood/ebb, drastically altering its features. This is a pioneering study on the phenomenon of "Fallen Lands" in the Amazonian environment. New studies, with more complex laboratory, field tests and geotechnical instrumentation for monitoring field need to be carried out. 


\section{Compliance with ethical standards}

\section{Acknowledgments}

The authors would like to thank the Canadian company GEOSLOPE and the Czech company FINE SOFTWARE, for using their software in student versions.

\section{Disclosure of conflict of interest}

No conflicts of interest identified by the authors regarding what is exposed in this article.

\section{References}

[1] Torres de Freitas, Francimara; Albuquerque, Adoréa Rebello da Cunha. Temporal Analysis on the "Fallen Lands" in the middle Solimões/Coari river - AM. Mercator - Journal of Geography of the Federal University of Ceará. Fortaleza: V. 11, N. 25, May-August, p. 129-140, 2012.

[2] Carvalho, José Alberto Lima de. Fallen Lands and social consequences: Costa do Miracauera ... Manaus: Federal University of Amazonas - UFAM. (Master's Dissertation in Society and Culture in the Amazon). 2006.

[3] Igreja, Hailton Luiz Siqueira da, Carvalho, José Alberto Lima de, Franzinelli, Elena. Aspects of Fallen Lands in the Amazon Region. In: RABELLO, Adoréa. Theoretical-Methodological Contributions of Physical Geography. Manaus: Publisher of the Federal University of Amazonas. 2010.

[4] Terzaghi, Karl. Theoretical Soil Mechanics. New York (USA): John Wiley and Sons. 1943.

[5] Vargas, Milton. Introduction to Soil Mechanics. São Paulo: McGraw-Hill do Brasil, Editora da Universidade de São Paulo. 1977.

[6] Caputo, H. P. Soil Mechanics and its Applications. Porto Alegre: Livros Técnicos e Científicos, 1966. 3 volumes.

[7] Venkatramaiah, C. Geotechnical Engineering. New Delhi (IND): New Age International. 2006.

[8] Tschebotarioff, Gregory Porphyriewitch. Foundations, Support structures São Paulo: McGraw-Hill do Brasil. 1978.

[9] Das, Braja M. Principles of Geotechnical Engineering. Stamford (USA): Cengage Learning. 2010.

[10] Bandeira Iris CN; et al. "Fallen Lands": Fluvial erosion or distinct phenomenon in the Amazon? Springer Environmental Earth Sciences. 2018.

[11] Nascimento Ricardo R, Simões Gustavo F. Assessment of the susceptibility to mass movements of watercourses in the city of Rio Branco (AC). Geosciences Magazine (UNESP). São Paulo. 2017; 36(2): 233-249.

[12] Lopes IR, Rodrigues FGS. Analysis of Fallen Lands on the Solimões River Banks in Tabatinga, AM. Geonorte Magazine. Manaus: Special Edition. 2014; 4(10): 55-59.

[13] Suguio, Kenitiro. Sedimentary geology. São Paulo: Blucher. 2003.

[14] Labadessa, Aparecido S. "Fallen Lands", the natural and anthropic causes: An occurrence in the community of São Carlos - Medium Madeira/RO. Geoingá Magazine (from the Graduate Program in Geography). Maringá. 2011; 3(1): 45-61. 